\title{
Prospective study on the occurrence and management of chronic sinoatrial disease, with follow-up ${ }^{1}$
}

\author{
R. Rokseth and L. Hatle \\ From the Section of Cardiology, Central Hospital, Trondheim, Norway
}

Sinoatrial disease can cause vague and intermittent symptoms and may be overlooked unless specially searched for. In a prospective study the disorder was found in 51 patients as against 98 with atrioventricular block, i.e. a relative incidence of 34 per cent. Several patients were referred from the neurologist. It is notable that rheumatic fever had occurred in 20 per cent. About 60 per cent had paroxysmal atrial fibrillation/tachycardia. Follow-up studies were carried out for an average period of 5 years after pacemaker implantation in 23 patients and during medical or no therapy in the remaining 28. Ventricular pacing abolished syncope and was often successful in preventing paroxysmal tachycardia without additional use of drugs. In most patients drug therapy alone was unsatisfactory. However, small doses of digitalis were used with fair success in 6 patients whose main trouble was paroxysmal tachycardia. In 5 others with bradycardia only, long-term oral isoprenaline prevented syncope without side effects.

Recent papers (Rokseth et al., 1970; Rasmussen, 1971; Rubenstein et al., 1972) have shown that chronic sinoatrial diseases may occur more frequently as a cause of troublesome symptoms than previously known. However, the reports were retrospective and the frequency of the disorder in relation to advanced atrioventricular block is uncertain. Sinoatrial disease can occur intermittently associated with vague symptoms and may not be detected unless specially and repeatedly looked for. The present report concerns a prospective study of $5 \mathbf{I}$ patients, with follow-up.

\section{Patients}

In a period of 5 years, I966 to 1970, all patients with chronic symptomatic sinoatrial disease (5I) and AV block (98) in our Department of Medicine were registered. Patients with spells of dizziness, syncope, or bradycardia were screened repetitively in order to detect intermittent block. A close collaboration was established with the Department of Neurology in order to exclude primary neurological causes. Incidentally, intermittent sinoatrial disease was detected in 6 patients after they had been referred to us because of unexplained 'cerebral' symptoms. The rhythm disorder was discovered by serial electrocardiograms or occasionally by tape recording. Follow-up examinations were made during an average of 5 years, the minimum period being 2.5 years. Received 17 December 1973.

1 This work was supported in part by a grant from the Norwegian Council on Cardiovascular Diseases.
Patients with arrhythmias discovered accidentally on routine electrocardiography, occurring during treatment with digitalis, quinidine, or other drugs, or associated with electrolyte disturbances, orthostatic hypotension, jaundice, myxoedema, acute myocardial infarction, or AV block of second or third degree, were excluded. The following criteria for sinoatrial disease were selected for inclusion in the study.

I) Second degree sinoatrial block (pauses between the $P$ waves being a multiple of the basic PP distance) persistent or intermittent.

2) Sinus arrest, here defined as periods of more than twice basic QRS distance ending in an escape beat.

3) Severe persistent sinus bradycardia when associated with recurrent syncope which could not be otherwise explained and was relieved by increasing heart rate.

The classification is arbitrary since sinus arrest and sinoatrial block cannot strictly be separated electrocardiographically. Under Results and in the Tables the 3 groups are treated together as there were no differences in the incidence of complications or results of therapy.

Second degree sinoatrial block was present in 30 patients: 13 of them had in addition sinus bradycardia (heart rate less than 55 a minute) and 5 had intermittent sinus arrest. Periods of sinus arrest were recorded in another 15 patients, 7 of whom had additional sinus bradycardia. Persistent severe sinus bradycardia was present in 5 patients and junctional rhythm in one who previously had periods of second degree sinoatrial block. The heart rate in these 6 patients was $42,40,40,37,28$, and 44, respectively. All of them had symptoms which 
were relieved by pacemaker therapy. Though the electrocardiogram was not recorded during syncope, sinoatrial disease was considered to be a reasonably certain explanation of their bradycardia and syncope.

Of the $5 \mathrm{I}$ patients, 3 had additional AV conduction disturbance (first degree block). Another 4 had complete right bundle-branch block, and 2 had left bundlebranch block. In 3 of these 6 patients bundle-branch block only occurred during periods of tachycardia.

The mean age was 62.4 years in 23 patients treated with pacemaker and 64.8 in 28 treated conservatively. All patients except one were above 40. There were 25 men, II treated without and 14 with pacemaker, and 26 women, 17 treated without and 9 with pacemaker; 14 patients previously described in more detail (Rokseth et al., 1970) were included in the present survey.

Rheumatic fever was the most common previous disease and had occurred in ro patients, while only 3 had had diphtheria. Seven patients had coronary disease, but syncope never occurred in connexion with chest pain. Three patients had moderate hypertension and one had mild aortic stenosis. Three others belonged to the same family.

Table I shows symptoms and complications. Thirtysix patients had syncope and 30 had paroxysmal atrial fibrillation flutter or atrial tachycardia. Ventricular tachycardia was not observed. The reasons for pacemaker implantation were repeated syncopal attacks, paroxysmal tachycardia, or both in 18 and chest pain and/or dyspnoea on exertion in the remaining 5 patients. Three of the 23 patients had signs of congestive heart failure.

Among the patients treated with a pacemaker, symptoms had lasted 3 to 21 years (mean 7 ) in 10 and less than 3 years in II. The exact duration was not known in 2. Among those treated conservatively the duration of symptoms was 3 to Io years (mean 5 ) in 12, less than 3 years in 10, and unknown in 6.

\section{Treatment}

\section{Pacemaker therapy}

Permanent pacing via intravenous electrode in the apex of the right ventricle was aimed at as previously described (Hatle and Rokseth, I97I). The pacemakers were fixed rate in the first II patients, QRS triggered in Io,

TABLE I Sinoatrial disease: symptoms in patients

\begin{tabular}{lll}
\hline & $\begin{array}{l}\text { Pacemaker } \\
\text { therapy (23) }\end{array}$ & $\begin{array}{l}\text { Conservative } \\
\text { therapy (28) }\end{array}$ \\
\hline Syncope & $19(16)$ & 17 (15) \\
Paroxysmal tachycardia & $13(4)$ & 17 (10) \\
Dyspnoea & $4(2)$ & 1 (1) \\
Angina pectoris & $5(3)$ & 3 (1) \\
\hline
\end{tabular}

In parenthesis: Number of patients with indicated symptom as the main complaint. In 2 patients in the left column syncope and paroxysmal tachycardia were equally troublesome. One patient not mentioned in the right column had slight dizziness only. and QRS inhibited in 2. In one of the latter, epicardial electrodes were applied during thoracotomy. The fixedrate pacemakers were later replaced by QRS triggered units in 6 patients because the electrocardiogram had shown interference phenomena though these were mostly unrecognized by the patients.

\section{Conservative therapy}

In patients without tachycardia and whose main complaint was syncope, oral treatment with atropine or isoprenaline was first attempted. Atropine was given in increasing doses up to $\mathrm{I} \mathrm{mg}$ four times daily to 6 patients. Isoprenaline was given in doses of $7.5 \mathrm{mg}$ or $15 \mathrm{mg} 4$ to 6 times daily to 17 patients and, if successful, replaced by long-acting isoprenaline, 15 to $30 \mathrm{mg}$, two or three times daily. Intravenous trials were not made but the effect of the first dose of isoprenaline was checked by monitoring or by counting the heart beat for $\mathbf{2}$ hours after administration. Moderate oral doses of digoxin were initially given to 14 patients whose main complaint was paroxysmal tachycardia. On rare occasions quinidine or procainamide was attempted.

\section{Results}

\section{Pacemaker therapy}

Syncopal attacks were abolished in all except 2 patients who developed orthostatic hypotension after pacemaker implantation. The symptoms were in both cases relieved by an ethylaminoetanchloride preparation (Effortil). One patient, a 50-year-old woman, who was found unconscious with a heart rate of 28 improved gradually during several weeks after pacemaker implantation but symptoms of slight brain damage persisted. Congestive heart failure in 3 patients disappeared in one and was improved in 2. Of 9 patients with chest pain and/or dyspnoea on exertion, 7 were completely relieved while the remaining 2 were improved. Among 13 patients with paroxysmal tachycardia 8 were completely free of attacks without additional drug therapy. The remaining 5 had occasional attacks of atrial fibrillation after pacemaker implantation and therefore received digitalis in addition. The attacks of tachycardia were significantly less frequent than previously. The first patient with alternating bradycardia and tachycardia who received a pacemaker (external fixed-rate) developed supraventricular tachycardia which was difficult to control. The electrode had to be removed, but several months later a demand unit was implanted with successful results when combined with digitalis. Two patients had severe wound infection in connexion with pacemaker implantation. Sepsis ensued in both and the pacemaker had to be removed in one while the other was successfully treated with antibiotics. In the first patient electrode dislocation 
occurred three times. Dislocation occurred in one additional patient. There were no other complications. Three patients died during the observation period, one suddenly 5 days after acute chest pain. Necropsy showed a large anterior infarction and a thrombus in the left coronary artery. The second patient had a previous myocardial infarction and died of congestive heart failure. The pacemakers had been implanted 18 to 22 months previously and there were no signs of malfunction. The third patient died of acute pulmonary oedema 2 months after pacemaker implantation. She had chronic polyarthritis, a murmur consistent with mitral insufficiency, and a heart volume of $1200 \mathrm{ml} / \mathrm{m}^{2}$. She had dyspnoea on slight exertion which was unchanged after pacemaker therapy. No necropsy was performed.

\section{Conservative therapy}

Table 2 summarizes the effect of oral drug therapy. Atropine had no effect in 4 patients and a transient effect only in the remaining 2. Isoprenaline was discontinued in 12 of 17 because of insufficient or no effect in 9 and because of attacks of atrial fibrillation or frequent ventricular premature beats which had not previously been noted in 3. These 12 patients later received a permanent pacemaker. In the remaining 5 patients, long-acting isoprenaline therapy had a satisfactory effect by raising the heart rate from 40 , to 60 to 70 a minute and abolishing symptoms; in 4, 15 to $30 \mathrm{mg}$ two or three times daily was successful in preventing syncopal attacks for an observation period of 4 to 6 years. They had previously had syncopal attacks 3 to 6 times a year. In the fifth patient who had 2 syncopal attacks one month before admission to hospital, $15 \mathrm{mg}$ longacting isoprenaline twice a day was successful in raising the heart rate and preventing the attacks, but after 2 years he began to feel discomfort and palpitation about half an hour after taking the drug. The dose was halved and the side effects disappeared while he was still symptom free in the remaining 8 months of the observation period.

Among the 28 conservatively treated patients, 4

TABLE 2 Drug therapy in sinoatrial disease

\begin{tabular}{llll}
\hline & $\begin{array}{l}\text { No. of } \\
\text { patients }\end{array}$ & $\begin{array}{l}\text { Useful } \\
\text { effect }\end{array}$ & $\begin{array}{l}\text { Side } \\
\text { effects }\end{array}$ \\
\hline Atropine & 6 & 0 & 0 \\
Isoprenaline & 17 & 5 & 3 \\
Digitalis & $14^{\star}$ & $6 \dagger$ & 3 \\
\hline
\end{tabular}

* Patients with paroxysmal atrial fibrillation/tachycardia.

† In 5 others useful effect when combined with pacemaker. whose main trouble was paroxysmal fibrillation received digitalis with fair success. Two additional patients received digitalis only during attacks of tachycardia. Among the patients who received a pacemaker, digitalis had been prescribed in 3 with paroxysmal atrial fibrillation, but was discontinued because of more pronounced bradycardia.

In 17 patients no treatment was considered necessary as they had either a single syncopal attack or only slight symptoms. No further attacks occurred and the condition otherwise remained unchanged during follow-up.

Three of the conservatively treated patients died in the observation period. One had ovarian metastatic cancer and the remaining 2 died at home of unknown causes at the age of 74 and 80 years, respectively. None of them died suddenly.

\section{Comments}

\section{Incidence}

Easley and Goldstein (197I) observed 13 cases with what they termed sinoatrial syncope in a prospective study of 200 patients with cardiovascular syncope. No previous report on the relative incidence of sinoatrial disease to AV block including both pacemaker and conservatively treated patients is available. Acute and transient sinoatrial disease occurring during acute myocardial infarction, as noted by Rossi (1962), was recently found by us in 32 of 1655 consecutive patients as against advanced AV block in 105, i.e. a relative incidence of 30 per cent (Hatle and Rokseth, 197I; Rokseth and Hatle, 1971). The relative incidence of chronic sinoatrial disease in the present study was roughly similar, 5I of 149 patients or 34 per cent. Most earlier reports on pacemaker series in chronic heart block contain only a few case studies of sinoatrial disease (Bayley, 197 I) or only a relatively small incidence (Bernstein, Rotem, and Peretz, 1971; Seremetis et al., I973). A recent report from Norway shows an incidence of ro per cent sinoatrial block in pacemaker-treated patients (Rasmussen, 197I), while the incidence in a Danish report was 23 per cent (Jensen et al., 1973). The latter report agrees with the present relative incidence in pacemaker treated patients of 24 per cent. The reason for these high numbers may be geographical variations or an increasing occurrence in the disorder, but the most likely explanation is the increasing awareness of the condition. Pacemaker-treated series, however, are composed of patients with severe symptoms and may not be representative, since sinoatrial disease may be overlooked as a cause of trouble. As recently stressed by Ferrer (1973) the disorder may have multifaceted and sometimes rather vague expressions. 


\section{Criteria and nomenclature}

Rasmussen (197I) included only patients with second degree SA block according to strict electrocardiographic criteria. It seems natural, however, in a clinical setting also to include patients with other electrocardiographic manifestations of sinoatrial disease. This is reflected by its many names, such as sick sinus syndrome (Lown, 1967), lazy sinus syndrome (Ginks and Oakley, r970), and sinoatrial disorder (Lloyd-Mostyn, Kidner, and Oram, 1973). Moreover, the incidence of various complications and results of therapy were similar in the three groups of criteria chosen in our study. Nor was there any difference regarding previous or associated diseases.

\section{Aetiology}

Sinoatrial disease associated with drugs was excluded from the present study. Otherwise, a variety of possible causes has been reported (LloydMostyn et al., 1973), but the aetiology often remains unknown. A notable feature of the present study is that Io patients, or 20 per cent, had previous rheumatic fever. In one series (Rasmussen, 197I) of 2 I patients, 6 had previously had diphtheria which was considered to be of aetiological importance. In the present study, however, diphtheria had occurred in only 3 of 51 patients. Others (Bouvrain, Slama, and Temkine, 1967; Slama et al., 1969) stress the importance of associated coronary disease which has been reported in up to 40 per cent (Rubenstein et al., 1972) and was present in 14 per cent of our patients. The disorder may also be familial (Rokseth et al., 1970; Lloyd-Mostyn et al., 1973).

\section{Age and sex}

The patients with sinoatrial disease were on an average about Io years younger than those with AV block when they came to our attention. The average duration of symptoms was about the same in both groups. There was no suggestion of a bimodal age distribution with a younger and older group as noted by some others (Slama et al., 1969; Rubenstein et al., 1972). The latter study, however, comprising 56 patients, also included 25 subjects with no symptoms. In the present study of $5 I$ patients as well as among 32 in the report by Slama et al. (1969) the number of men and women were about equal while there were more women than men in the studies of Rasmussen (197I) and Rubenstein et al. (1972).

\section{Complications and natural course}

Ventricular tachycardia was noted by Slama et al. (1969) in 2 patients but was not observed by us. AV conduction disturbances were found in 19 of 56 patients by Rubenstein et al. (1972). Only 3 of our patients had first degree AV block, while 2 others with advanced AV block were not included. This is more in agreement with Slama et al. (1969) who found AV conduction disturbances in 6 of their patients. However, Narula (197I) using His bundle records found AV conduction abnormalities in 67 per cent of 75 patients with sinus bradycardia.

Cerebrovascular accidents were observed in Io patients by Rubenstein et al. (1972). In 8 cases the strokes were thought to be due to emboli. Samarasinghe and Senanayake (1973) reported two cases of sinoatrial disease complicated by neurological manifestations leading to long-lasting disability. In one case a demand pacemaker completely abolished the recurrent symptoms. Severe cerebrovascular symptoms occurred in only one patient in the present study. The condition was improved after pacemaker therapy but slight symptoms of brain damage persisted.

The association of sinus bradycardia and angina pectoris was noted by Fowler et al. (1969) in a patient whose angina was abolished by atrial pacing. Similarly, chest pain or dyspnoea on exertion in 5 of the present patients was relieved by raising the heart rate.

The most conspicuous complication in the present study was paroxysmal atrial fibrillation/tachycardia which occurred in 30 of 51 patients. Eraut and Shaw (1971) observed fast atrial arrhythmia in 12 of 46 patients with sinus bradycardia (heart rate less than 56 a minute). This occurrence of alternating bradycardia and tachycardia was described by Levine (I916), Laake (1946), and Short (I954), and has since been reported in increasing numbers, the largest single report comprising 32 patients collected during several years by Slama et al. (1969). An interesting natural course was noted by Stock (1969) in 2 patients with SA block who spontaneously developed permanent atrial fibrillation and then lost their syncopal attacks. Such a course was not observed in the present series. However, one of 30 later patients (unpublished data) with sinoatrial disease developed atrial fibrillation which has persisted for the past 9 months. The patient received long-acting isoprenaline $30 \mathrm{mg}$ twice daily. Because syncopal attacks recurred the dose was doubled. Atrial fibrillation appeared about 30 minutes after the first of these higher doses. The drug was discontinued and she has had no further syncope.

Generally, sinoatrial disease carries a more benign prognosis than AV block. However, the course may also be malignant and major AdamsStokes attacks may occur after long periods with an apparently benign course (Rasmussen, 1971). 
Narula (197I) restudied I4 patients with His bundle recording and observed prolongation of conduction times over $1 \frac{1}{2}$ to 2 years in 3 of them.

\section{Therapy}

Pacemaker therapy was effective in relieving syncope in all our patients. Contrary to the experience of Rubenstein et al. (1972) where pacemaker therapy alone usually did not abolish paroxysmal tachycardia, it was successful in more than half of our patients with alternating bradycardia and tachycardia. In the remainder, additional drug therapy was necessary. Since the early reports by Cohen, Kahn, and Donoso (1967), Cheng (1968), Sandøe and Flensted-Jensen (1969), Sowton et al. (1969), and Rokseth et al. (1970), several papers have dealt with the successful use of pacemakers often combined with cardiosuppressive drugs in treating this syndrome. As referred to by Bayley (197I) two relevant points may be raised regarding ventricular pacing in treating sinoatrial disease. First, the occurrence of parasystole with the risk of provoking ventricular tachycardia has proved to be of little significance and was not observed in the present series. Secondly, ventricular pacing causes loss of atrial transport function which may depress cardiac output. This was not clinically detected in any of the present patients. On the contrary, congestive heart failure improved when the heart rate was raised. It should be recalled that one patient died of pulmonary oedema 2 months after pacemaker implantation. She had, however, prior severe congestive heart failure. It should also be noted that 2 of our patients developed orthostatic hypotension during pacemaker therapy. One of our later patients with sinoatrial disease and syncope (unpublished), where an electrode was placed in the right ventricle, developed severe hypotension immediately after a demand pacemaker was turned on. The blood pressure rose to previous values when the pacemaker was turned off. When the procedure was repeated the same thing happened again and the electrode was removed. She later died of bronchial carcinoma infiltrating the atria but the heart was otherwise normal. The unexpected response to pacing remains unexplained. Similar severe hypotension related to retrograde VA conduction during demand pacing was reported in a patient by Rubenstein et al. (1972).

The difficulties of drug therapy in sinoatrial disease were stressed long ago by Greenwood and Finkelstein (1964). There are few reports on the use of long-acting isoprenaline. Ferrer (I968) states that long-term treatment with stimulators of sinus rate is not practical. Isoprenaline was tried in 17 of our patients and had to be discontinued in 12 . It is of interest, however, that the remaining 5 patients have been successfully treated for an average of 5 years.

\section{References}

Bayley, T. J. (1971). Long-term ventricular pacing in treatment of sinoatrial block. British Medical fournal, 3, 456.

Bernstein, V., Rotem, C. E., and Peretz, D. I. (1971). Permanent pacemakers: 8-year follow-up study. Annals of Internal Medicine, 74, 36I.

Bouvrain, Y., Slama, R., and Temkine, J. (1967). Le bloc sinoauriculaire et les 'maladies du sinus'. Archives des Maladies du Coeur et des Vaisseaux, 60, 753.

Cheng, T. O. (1968). Transvenous ventricular pacing in the treatment of paroxysmal atrial tachyarrhythmias alternating with sinus bradycardia and standstill. American fournal of Cardiology, 22, 874.

Cohen, H. E., Kahn, M., and Donoso, E. (1967). Treatment of supraventricular tachycardias with catheter and permanent pacemakers. American fournal of Cardiology, 20, 735.

Easley, R. M., Jr., and Goldstein, S. (197I) Sino-atrial syncope. American fournal of Medicine, 50, 166.

Eraut, D., and Shaw, D. B. (1971). Sinus bradycardia. British Heart fournal, 33, 742.

Ferrer, M. I. (1968). The sick sinus syndrome in atrial disease. Fournal of the American Medical Association, 206, 645.

Ferrer, M. I. (1973). The sick sinus syndrome. Circulation, 47, 635.

Fowler, P. B. S., Ikram, H., Maini, R. N., Makey, A. R., and Kirkham, J. S. (1969). Bradycardic angina: haemodynamic aspects and treatment. British Medical fournal, I, 92.

Ginks, W. R., and Oakley, C. M. (1970). Lazy sinus syndrome. Proceedings of the Royal Society of Medicine, 63, 1307.

Greenwood, R. J., and Finkelstein, D. (1964). Sinoatrial Heart Block, p. 70. Charles C. Thomas, Springfield, Illinois.

Hatle, L., and Rokseth, R. (197I). Conservative treatment of AV block in acute myocardial infarction. Results in 105 consecutive patients. British Heart fournal, 33, 595.

Jensen, G., Sigurd, B., Meibom, J., and Sandøe, E. (1973). Adams-Stokes syndrome caused by paroxysmal thirddegree atrioventricular block. British Heart fournal, 35, 516.

Laake, H. (1946). A case of paroxysmal auricular tachycardia with sino-auricular and atrio-ventricular block. Acta Medica Scandinavica, 124, 52.

Levine, S. A. (1916). Observation on sino-auricular heart block. Archives of Internal Medicine, 17, 153.

Lloyd-Mostyn, R. H., Kidner, P. H., and Oram, S. (1973). Sinuatrial disorder including the brady-tachycardia syndrome. Quarterly fournal of Medicine, 42, 41.

Lown, B. (1967). Electrical reversion of cardiac arrhythmias. British Heart fournal, 29, 469.

Narula, O. S. (1971). Atrioventricular conduction defects in patients with sinus bradycardia. Circulation, 44, 1096.

Rasmussen, K. (1971). Chronic sinoatrial heart block. American Heart fournal, 81, 38.

Rokseth, R., and Hatle, L. (197I). Sinus arrest in acute myocardial infarction. British Heart fournal, 33, 639.

Rokseth, R., Hatle, L., Gedde-Dahl, D. and Foss, P. O. (1970). Pacemaker therapy in sino-atrial block complicated by paroxysmal tachycardia. British Heart fournal, 32, 93 .

Rossi, L. (1962). Infarction of the sinu-atrial node. British Medical fournal, 2, 927.

Rubenstein, J. J., Schulman, C. L., Yurchak, P. M., and DeSanctis, R. W. (1972). Clinical spectrum of the sick sinus syndrome. Circulation, 46, 5. 
Samarasinghe, H. H. R., and Senanayake, N. (1973). Permanent neurological deficits complicating sinoatrial block. British Heart Fournal, 35, 503.

Sandøe, E., and Flensted-Jensen, E. (1969). Adams-Stokes seizures in patients with attacks of both tachy- and bradycardia, a therapeutical challenge. Acta Medica Scandinavica, 186, III.

Seremetis, M. G., deGuzman, V. C., Lyons, W. S., and Peabody, J. W., Jr. (1973). Cardiac pacemakers. Clinical experience with 289 patients. American Heart fournal, 85, 739.

Short, D. S. (1954). The syndrome of alternating bradycardia and tachycardia. British Heart fournal, 16, 208.
Slama, R., Waynberger, M., Motte, G., and Bouvrain, Y. (1969). La maladie rythmique auriculaire. Etude clinique, électrique et évolutive de 43 observations. Archives des Maladies du Coeur et des Vaisseaux, 62, 297.

Sowton, E., Balcon, R., Preston, T., Leaver, D., and Yacoub, M. (1969). Long-term control of intractable supraventricular tachycardia by ventricular pacing. British Heart fournal, 31, 700 .

Stock, J. P. P. (1969). Diagnosis and Treatment of Cardiac Arrhythmias, p. 187. Butterworths, London.

Requests for reprints to Dr. R. Rokseth, Section of Cardiology, Central Hospital, 7000 Trondheim, Norway. 